\title{
Annual and hybrid ryegrass cultivars in New Zealand
}

\author{
SYD EASTON $^{1}$, DAVID BAIRD ${ }^{2}$, GORDON BAXTER $^{3}$, NICK CAMERON $^{4}$, \\ ROBYN HAINSWORTH ${ }^{5}$, CHRISTINE JOHNSTON ${ }^{6}$, GRAHAM KERR ${ }^{6}$, TOM LYONS ${ }^{1}$, \\ ROSLYN MCCABE ${ }^{7}$, WAYNE NICHOL ${ }^{8}$, MICHAEL NORRISS $^{9}$, ALAN STEWART $^{10}$ \\ and ERROL THOM ${ }^{7}$ \\ ${ }^{1}$ AgResearch, Grasslands Research Centre, PB 11008, Palmerston North \\ ${ }^{2}$ AgResearch, Canterbury Agriculture and Science Centre, PO Box 60, Lincoln \\ ${ }^{3}$ AgResearch, Gore* \\ ${ }^{4}$ Hodder \& Tolley Ltd, Canterbury** \\ ${ }^{5}$ Taranaki Agricultural Research Station, PO Box 711, Hawera \\ ${ }^{6} \mathrm{NZ}$ Agriseeds Ltd, Old West Coast Road, RD 1, Christchurch \\ ${ }^{7}$ Dairying Research Corporation, Private Bag 3123, Hamilton \\ ${ }^{8}$ Hodder \& Tolley Ltd, Canterbury $\dagger$ \\ ${ }^{9}$ Wrightson Nutrition, PO Box 939, Christchurch \\ ${ }^{10}$ Pyne Gould Guinness, PO Box 6068, Christchurch 8004
}

\footnotetext{
* Present address: 3 Pukaki St, Gore

** Present address: Cropmark NZ, Auchenflower Road, RD 1, Darfield

$\dagger$ Present address: Wrightson Nutrition, PO Box 939, Christchurch

† Present address: Livestock Improvement Corporation, 19 King Edward Drive, Eltham
}

\begin{abstract}
Results are presented for 16 National Forage Variety Trials of annual and short-term hybrid ryegrass cultivars conducted in Waikato, Taranaki, Manawatu, Canterbury and Southland. In all, 30 cultivars (17 named, 13 experimental) were included. Cultivar effects were significant in all seasons, and for the annual totals. Cultivar differences were greatest in summer. Spring production accounted for over $40 \%$ of annual totals and summer production less than $20 \%$, but it was summer production that was more closely correlated with the individual cultivar annual total. Over all trials and cultivars, regrowth in the second autumn accounted for $11 \%$ of the total for 12 months beginning in the winter following sowing. Comparing North Island sites with Canterbury sites, there was some indication of cultivar $\times$ region interaction, particularly in summer. Patterns of interaction of cultivars with trials were examined, and indicated that some cultivars can be grouped as having similar responses. Repeated trials at the same site were sometimes but not always consistent in ranking cultivars. The results indicate that some cultivars do perform consistently better than others, for particular seasons or for annual totals, so that the trials are a reliable indicator of which new experimental cultivars should be released to the market. The results also indicate that several trials are necessary to determine the merit of a well-
\end{abstract}

performing cultivar. The error associated with the mean of cultivars present in only one or two trials is high (standard deviation approaching 20\% of the mean in some seasons). This may, however, be sufficient to eliminate poorer experimental lines from further consideration.

Keywords: Italian ryegrass, hybrid ryegrass, cultivars, Lolium $\times$ boucheanum, Lolium multiflorum, pasture agronomy

\section{Introduction}

Italian ryegrass (Lolium multiflorum Lam.) has been used in New Zealand since pastures were first sown. Short-term hybrid ryegrasses $(L . \times$ boucheanum Kunth.) were identified among New Zealand seed stocks in the 1920s (Levy \& Davies 1929). Just under 3000 tonnes of seed of these two groups together are currently certified annually in New Zealand (MAF 1997), compared with nearly 12000 tonnes of perennial ryegrass. They are sown either in specialist short-term pastures, or included in perennial pasture seed mixtures, to provide a good bulk of quality feed in the first winter.

Levy and colleagues studied seed sources of pasture species available in New Zealand in the 1920s. Almost no genuine Italian ryegrass lines were found in commerce (Corkill 1949). Imported varieties of Italian ryegrass proved to be superior to material then available in New Zealand (Levy \& Saxby 1933), and after the introduction of a certification system in 1929/30, the best imported 
varieties were multiplied under certification. A selected pedigree strain of Italian ryegrass was first certified in New Zealand in 1938, and it proved to be superior to existing certified commercial strains (Corkill 1949).

Levy and co-workers did not identify any naturally evolved populations of Italian ryegrass in commerce, but noted that good populations persisted by natural reseeding in some New Zealand pastures (Levy 1932). Valuable sources have more recently been shown to exist (Burgess \& Easton 1986), and cultivar (cv.) Concord was the first Italian ryegrass cultivar to be developed from material naturally adapted to New Zealand conditions.

Natural populations of ryegrass in New Zealand show varying degrees of hybrid origin between the Italian and perennial species (Levy \& Davies 1929). Forde et al. (1988) compared descriptive traits of Italian ryegrass cultivars. They found the Te Puna ecotype (from which cv. Corvette was derived) to be similar in most descriptive characters to Grasslands Manawa hybrid ryegrass. They also noted, however, that their results showed no clear discontinuities in the range of cultivars examined. While some sources and cultivars are clearly distinct from Italian ryegrass, the classification of others as either Italian or hybrid ryegrass does not secure unanimity.

Italian ryegrass cultivars from overseas were compared by Rumball \& Armstrong (1975) who concluded that none were superior to New Zealand cultivars. This situation remains generally true (unpublished data), and only one imported cultivar is currently marketed in New Zealand.

Forde et al. (1988) found that New Zealand ecotypes and cultivars developed from them tended to be faster to germinate and establish than cultivars developed from imported material. These same ecotypes and cultivars were infected with the Italian ryegrass endophyte (Latch $e t$ al. 1988). Examination of old seed of Grasslands Paroa showed that this cultivar had also once been infected with endophyte.

Hickey \& Baxter (1989), Hume \& Hickey (1989) and Hickey \& Hume (1994) compared cultivars grown at Gore and Palmerston North. All cultivars persisted better in the summer-moist conditions of Southland, but the yield and persistence of $\mathrm{cv}$. Concord and cv Corvette (classified as hybrid by these authors) relative to those of Paroa and Grasslands Moata were greater at Palmerston North than at Gore.

The New Zealand Plant Breeding and Research Association co-ordinates co-operative trials (National Forage Variety Trials) comparing commercial and experimental cultivars of Italian and short-lived hybrid ryegrasses at a range of sites throughout New Zealand. This paper presents results from 16 trials carried out from 1990 to 1996.

\section{Materials and methods}

Trials are listed in Table 1 with location, sowing date, number of entries and management.

Trials were sown into well prepared seed-beds on land immediately out of a non-ryegrass crop, or which had been rigorously controlled over the previous season to prevent any return of ryegrass seed to the soil. Base fertiliser was applied to each trial as indicated by soil analysis. Plot size varied between trials, being largest in trials grazed by cattle, but was at least $3.6 \mathrm{~m} \times 0.75 \mathrm{~m}$ in all trials. Where necessary, volunteer species were controlled by herbicide. All trials were laid out as randomised complete blocks, with cultivar the only factor.

Table 1 List of trials with management details.

\begin{tabular}{lccccc}
\hline Trial & Location & $\begin{array}{c}\text { Sowing } \\
\text { date }\end{array}$ & $\begin{array}{c}\text { No } \\
\text { harvests }\end{array}$ & Management & $\begin{array}{c}\text { No } \\
\text { entries }\end{array}$ \\
\hline A291 H0D & Canterbury & 13.3 .91 & 6 & mown & 7 \\
A291 PAL & Manawatu & 13.3 .91 & 6 & mown & 10 \\
A291 PGG & Canterbury & 18.3 .91 & 8 & mown & 10 \\
A291 RUK & Waikato & 21.3 .91 & 10 & mown & 7 \\
A292PGG & Canterbury & 12.3 .92 & 8 & mown & 13 \\
A292RUA & Waikato & 13.3 .92 & 13 & mown & 11 \\
A293G0R & Southland & 10.3 .93 & $19 *$ & mown & 9 \\
A293 PGG & Canterbury & 17.3 .93 & 7 & mown & 12 \\
A293RUA & Waikato & 23.3 .93 & 12 & mown & 11 \\
A294KIM & Canterbury & 1.3 .94 & 10 & mown & 11 \\
A294NOR & Taranaki & 21.4 .94 & 9 & mown & 8 \\
A294RUA & Waikato & 14.3 .94 & 12 & grazed cattle & 12 \\
A295GOR & Southland & 7.3 .95 & 11 & mown & 4 \\
A295KIM & Canterbury & 22.2 .95 & 12 & mown & 11 \\
A295NOR & Taranaki & 23.3 .95 & 8 & mown & 5 \\
A295RUA & Waikato & 14.3 .95 & 10 & mown & 12 \\
\hline
\end{tabular}

1 Trial ran for two years

Table 2 Cultivars tested, with number of trials in which each was present.

\begin{tabular}{lclclcllll}
\hline AGR902 & 4 & Cordura & 8 & Flanker & 7 & Moata & 9 & PG203 & 2 \\
AGR906 & 3 & Corvette & 15 & Galaxy & 8 & NZALM28 & 5 & PG31 & 3 \\
Atlantis & 3 & CS3566 & 2 & Geyser & 12 & NZALM37 & 3 & PGRR & 1 \\
Concord & 16 & Decanter & 2 & 12 & 2 & PGI9 & 1 & Progrow & 7 \\
Conker & 7 & Eclipse & 4 & Maverick Gold & 1 & PG201 & 1 & Roberta & 2 \\
Conquest & 6 & Exalta & 16 & Maxima & 1 & PG202 & 1 & VP61 & 1 \\
\hline
\end{tabular}


A total of 30 cultivars (some in commerce, others experimental) were examined in the trials (Table 2). In North Island and Canterbury trials, but not in Southland, Ceres Geyser and Ceres Galaxy were infected with the endophyte, Neotyphodium lolii, typically associated with perennial ryegrass. Two cultivars were present in all trials, and another 9 were present in 6 or more trials. Seven cultivars were present in only one trial.

Seed was supplied by owners or licensees of the cultivars. Seed was drilled into plots or broadcast and covered. Trials were visited by representatives of interested parties soon after establishment to maintain confidence that emergence was satisfactory.

A standard management protocol was followed, requiring adjustment of sowing rate to give equivalent weight of viable seed per $\mathrm{m}^{2}$, with a $30 \%$ increase for tetraploid cultivars. Trials were harvested when heaviest plots carried between 2000 and $3000 \mathrm{~kg} \mathrm{DM} / \mathrm{ha}$, and nitrogen was applied after each harvest at $3 \%$ of mean dry matter removed from the highestyielding cultivar at the time. Plots in one Waikato trial were grazed as quickly as possible by fasted animals. Elsewhere, they were mown off. All trials were sown in autumn and ran for 15 months, except for one trial at Gore, Southland, which ran for an extra year. Data from the second year were not included in the analysis presented here. Dry matter production was measured directly by cutting, or assessed by appropriately calibrated capacitance probes.

Each trial was analysed using GENSTAT, analysing first for harvest and replicate, and then for cultivar within harvest. Data were then combined and analysed across all trials, with estimation of adjusted means for cultivars. Harvests were combined within seasons to give an establishment total and four seasonal totals. Yields for harvest periods straddling seasons were assigned according to the number of days in each season. Trials were assigned to three regions (North Island, Canterbury, Southland) and data were analysed for interactions between cultivar and region. Finally, cultivars and trials were clustered into dendrogrammes to indicate which cultivars were most similar in their performance across trials, and which trials were most similar in their annual and seasonal ranking of cultivars.

\section{Results}

Trials were run very satisfactorily, with coefficients of variation for individual harvests generally no larger than $15 \%$. Cultivars present in 6 or fewer trials had standard errors of overall mean at least twice those of cultivars present in most trials. Cultivars present in only one trial had standard errors of mean of $10 \%$ for winter and spring production, $20 \%$ for summer and $30 \%$ for autumn. Only cultivars present in 6 or more trials are shown in Tables 3 and 4.

\begin{tabular}{lccccccc}
\hline $\begin{array}{l}\text { Number } \\
\text { of trials }\end{array}$ & $\begin{array}{c}\text { Establish- } \\
\text { ment }\end{array}$ & winter & spring & summer & autumn & Total \\
\hline Concord & 16 & 110 & 96 & 94 & 97 & 103 & 12823 \\
Conker & 7 & 99 & 99 & 96 & 98 & 98 & 12977 \\
Conquest & 6 & 101 & 94 & 89 & 86 & 93 & 11965 \\
Cordura & 8 & 100 & 99 & 107 & 125 & 126 & 14848 \\
Corvette & 15 & 101 & 109 & 110 & 113 & 108 & 14706 \\
Exalta & 16 & 99 & 107 & 102 & 81 & 54 & 12456 \\
Flanker & 7 & 106 & 105 & 107 & 119 & 119 & 14732 \\
Galaxy & 8 & 91 & 103 & 107 & 127 & 140 & 15184 \\
Geyser & 12 & 89 & 92 & 98 & 114 & 121 & 13665 \\
Moata & 9 & 95 & 98 & 100 & 82 & 76 & 12393 \\
Progrow & 7 & 108 & 97 & 90 & 59 & 61 & 10830 \\
Mean yield kg DM/ha & 1960 & 3008 & 5970 & 2900 & 1448 & 13325 \\
\% of total & & 23 & 45 & 22 & 11 & & \\
\hline
\end{tabular}

Table 4 Relative mean summer yields of cultivars in different regions $\%$ of regional mean.

\begin{tabular}{lcccc}
\hline & Southland & Canterbury & Nth Island & Overall \\
\hline Concord & 101 & 112 & 79 & 98 \\
Conker & 93 & 107 & 78 & 94 \\
Conquest & & 112 & 57 & 92 \\
Cordura & 111 & 113 & 138 & 120 \\
Corvette & 106 & 100 & 130 & 112 \\
Exalta & 103 & 73 & 73 & 82 \\
Flanker & & 105 & 138 & 116 \\
Galaxy & 107 & 112 & 150 & 122 \\
Geyser & 88 & 108 & 140 & 113 \\
Moata & 90 & 89 & 77 & 85 \\
Progrow & & 69 & 41 & 65 \\
\hline
\end{tabular}

Cultivar effects were significant across harvests in all trials, and cultivar $\times$ harvest interactions were significant in all trials but one. When all trials were analysed together, cultivar effects were significant in each season (Table 3 ), and there was a significant cultivar $x$ season interaction.

In the establishment period (up to the end of May in the year of sowing), in winter and in spring, the 
range of performance was much the same, some cultivars producing $25 \%$ more than others. In summer and autumn, the stronger cultivars yielded twice as well as the weakest cultivars. Spring yield accounted for $45 \%$ of the total after the establishment period and summer only $22 \%$, but cultivar spring yield was not as highly correlated with the annual total as was summer yield. Summer yield was correlated with spring and autumn yields, and these seasons were correlated with the annual total. Winter yield was correlated with spring yield. Yield in the establishment period was not correlated with any other season. Yield in the autumn 12 months after sowing accounted on average for $11 \%$ of total yield after the establishment period.

Region effects were significant in all seasons against residual error, but were greater than trial-within-region effects only in summer. Cultivar $\times$ region effects were significant against residual error, only after removal of trial-within-region effects, in spring, summer (Table 4) and annual totals, but not for establishment, winter or the second autumn.

The dendrogramme of trials (Figure 1) produced by the clustering exercise did not clearly group trials within a region or consistently group trials at one site. It identified the single trial in Manawatu (Palmerston North) as the most distinct from all others. A peculiarity of this trial was very good performance by $\mathrm{cv}$. Exalta, particularly in summer. The clustering of cultivars (Figure 2) separated the erect open cultivars Exalta and Grasslands Moata from the others and from each other, and placed the Westerwolds cultivar Ceres Progrow with an experimental line NZALM28 but distinct from others. Concord, Conquest and Eclipse were grouped together, while Corvette, Galaxy, Cordura and Flanker were identified as another group. Note, however, that no assessment of statistical significance can be made for these observations.

\section{Discussion}

Yield in agronomic trials is an indicator of the ability of a cultivar to provide nutrition for the maintenance, growth and milk production of livestock. Kilograms of dry matter per hectare do not necessarily translate into livestock production (Thom \& Bryant 1996), and yield data must be interpreted according to the seasonal needs of a particular livestock enterprise.

The data show the value of a network of trials, in giving confidence in the seasonal and total yield of new cultivars about to be commercialised. Four to six trials could indicate a promising trend of a new cultivar to yield well relative to a control, and justify commercialisation. In a few cases, one or two trials were sufficient to indicate that an experimental cultivar did not merit further examination. Farmers should not
Figure 1 Dendrogramme grouping trials according to similarity of cultivar performance.

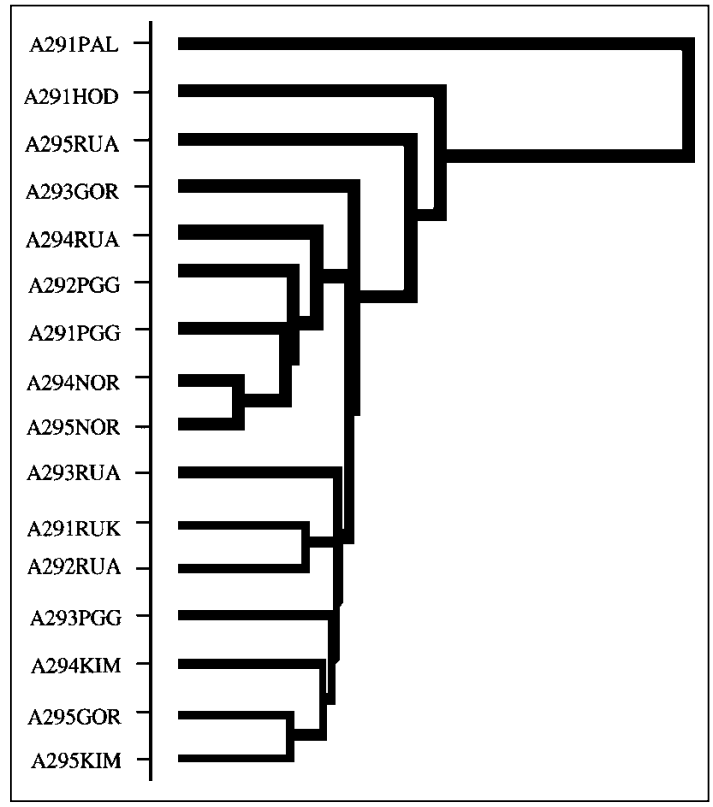

Figure 2 Dendrogramme grouping cultivars according to performance across trials.

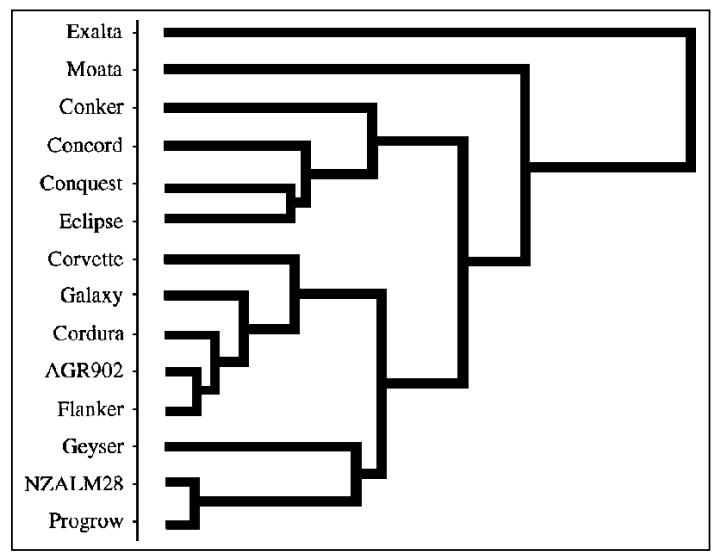

accept the value of a cultivar on the basis of one or two trials.

The failure of the clustering analysis to clearly associate trials from the same region indicates that the national mean performance may be of more value to a farmer in indicating performance than a small number of trials within a district.

The data also indicate that progress has been made in improving Italian and short-term hybrid ryegrasses. When Moata was developed it was clearly superior to 
any other Italian ryegrass material available (Armstrong \& Rumball 1975, who refer to it as G4709). Almost all cultivars in Table 3 out-yielded Moata, with most of the improvement in summer and autumn. Corkill (1950) reported seasonal yields of pedigree strains of Italian ryegrass, and showed summer yield as less than one third of that in the spring. Table 3 indicates that there has been significant progress in this respect.

The interaction of cultivar and season is seen in the relative seasonal performance of different cultivars. Conker yielded close to the mean in all seasons. Exalta, Moata and especially the Westerwolds cultivar Ceres Progrow, performed relatively better in winter and spring than in summer and autumn, whereas Cordura, Flanker, Ceres Galaxy and Ceres Geyser yielded relatively much better in summer and autumn than they did in the earlier seasons. Endophyte infection of these last two may have afforded resistance to insect pressure (Prestidge et al. 1994) and contributed to their summer and autumn performance. A choice of infected or uninfected seed lines of these cultivars is available in commerce. Corvette yielded well in all seasons, but while it was top of the trial in winter and spring, it was outperformed by four other cultivars in summer and autumn. In absolute terms, all cultivars produced more herbage in spring than in other seasons.

There is a range of nearly $20 \%$ between cultivars in mean spring yield over all trials. Yields in other seasons are lower than in spring, but there is a greater range, particularly in summer and the second autumn. Cultivars should be chosen for the strengths which meet the needs of a particular farm operation. In this set of data, Concord showed particularly good establishment and Exalta performed better in winter than in other seasons. Generally, however, summer and autumn were the seasons which separated the cultivars.

Some differences in regional adaptation for summer production are evident (Table 4), with Concord, Conker and Conquest performing relatively better in Canterbury, while Cordura, Corvette, Flanker, Galaxy and Geyser performed relatively better in the North Island.

The clustering of cultivars (Figure 2) is of interest. Concord, Conquest and Eclipse are related. Cordura is derived from Corvette and, like Corvette, Flanker is derived from ecotype material from the Waikato-Bay of Plenty area. These common origins are reflected in similar patterns of performance across the trials.

\section{REFERENCES}

Burgess, R.E.; Easton H.S. 1986. Old pasture populations of ryegrass in New Zealand and their use in plant breeding. pp. 295-300 In Proceedings of a Plant Breeding Symposium DSIR 1986, Lincoln, New Zealand. Williams, T.A.; Wratt G.S. (eds.) Special Publication 5, Agronomy Society of New Zealand.

Corkill, L. 1949. Recent development in the ryegrasses. Proceedings of the New Zealand Grassland Association 11: 140-150.

Corkill, L. 1950. Pedigree strains of pasture plants. Grasslands Bulletin no. 3, New Zealand, DSIR.

Forde, M.B.; Burgess, R.E.; Halligan, E.A.; Gardiner, S.E.; Latch, G.C.M. 1988. Varieties of Italian ryegrass in New Zealand. Proceedings of the New Zealand Grassland Association 49: 101-106.

Hickey, M.J., Baxter, G.S. 1989.Winter feed value of 'Grasslands Moata' tetraploid Italian ryegrass in Southland. Proceedings of the New Zealand Grassland Association 50: 225-230.

Hickey, M.J., Hume, D.E. 1994. Evaluation of seven Italian and hybrid ryegrasses under sheep grazing in Southland, New Zealand. New Zealand journal of agricultural research 37: 495-508.

Hume, D.E.; Hickey, M.J. 1989. Pasture production of annual, hybrid and perennial ryegrasses in cool and warm temperate climates.. Proceedings of the XVII International Grassland Congress: 1323-1325.

Latch, G.C.M.; Christensen, M.J.; Hickson, R.E. 1988. Endophytes of annual and hybrid ryegrasses. New Zealand journal of agricultural research 31: 57-63.

Levy, E.B. 1932. New Zealand pasture seeds. What the dominion has to offer. New Zealand journal of agriculture 44: 253-260.

Levy, E.B.; Davies, W.M. 1929. Strain investigation relative to grasses and clovers. New Zealand journal of agriculture 39: 1-8.

Levy, E.B.; Saxby, S.H. 1933. Strain investigation of grasses and clovers. Italian, Western Wolths and Wimmera ryegrasses. New Zealand journal of agriculture 47: 366-375.

Prestidge, R.A.; Popay, A.J.; Ball, O.J.-P 1994. Biological control of pastoral pests using Acremonium spp. endophytes. Proceedings of the New Zealand Grassland Association 56: 33-38.

Rumball, W.; Armstrong, C.S. 1975. The performance of overseas ryegrass cultivars in New Zealand. Proceedings of the New Zealand Grassland Association 36: 97-104.

Thom, E.R.; Bryant, A.M. 1996. Use of Italian ryegrass on seasonal dairy farms in northern New Zealand. 2. Milk production. New Zealand journal of agricultural research 39: 237-244. 
